\title{
Food Access and Dietary Variety Among Older People.
}

\section{Lisa C Wilson, Andrew Alexander and Margaret Lumbers School of Management University of Surrey}

This is an author copy of a paper published in International Journal of Retail \& Distribution Management Vol.32, Number 2, $109-122$ (2004). As such its format may differ from the final version published in the journal. Tables and Figures are provided at the end of the paper. 


\title{
Food Access and Dietary Variety Among Older People.
}

\begin{abstract}
Decentralisation of many food retailers to edge-of-town and out-of-town locations has resulted in some older people experiencing difficulty in accessing food shops and those experiencing greatest difficulties in food shopping are considered to be at the greatest nutritional risk.
\end{abstract}

The present study examines how and to what extent usage of, and physical access to food shops might influence dietary variety. Shopping behaviour and dietary variety are investigated using focus groups, a consumer questionnaire and a food frequency questionnaire (FFQ). A dietary variety score system, developed from the FFQ, is employed in this study.

Neither usage of (particular) food shops nor basic accessibility variables are found to have a direct effect on dietary variety. Yet, coping strategies employed by older consumers to obtain food are revealed to be important. This suggests that more complex access factors remain an important issue for study in relation to the shopping experience of a proportion of the older population.

\section{$\underline{\text { Introduction }}$}

In the year 2000 the UK population numbered 59.8 million people of which 10.8 million were over retirement age (60 years of age for women, 65 years of age for 
men) (Office of National Statistics, 2002). The ONS predicts a UK population of 64.1 million people by 2021 , of which 12.3 million will be over pensionable age. Such predictions reveal older people to be one of the fastest growing sections of the UK population.

Older people have been recognised as a disadvantaged group with regard to their ability to access food shops (Westlake, 1993; Bromley and Thomas, 1995). This paper considers the influence of older people's access to and usage of food shops on the variety found in their diet. A review of the literature relating to the geography of food retailing, accessibility and older consumers, and health and dietary variety is presented. Following this, the paper reports on the use of focus groups, consumer questionnaires and a food frequency questionnaire (FFQ) in a recent study to examine food access and dietary variety among older people. Lastly, results derived from these methods are reported with discussion of the main findings.

\section{The Changing Geography of Food Retailing}

Changes to food retail provision in the UK have been well documented by academics from disciplinary backgrounds including Geography, Business and Management Studies and Urban and Regional Planning (see for instance Guy, 1994; Davies and 
Sparks, 1989; Wrigley, 1998a). Among the most significant of these changes has been the relocation of a considerable amount of food retail capacity away from town centre locations to larger store developments at edge-of-town and out-of-town sites. This process started during the 1970 s, but it was during the 1980s that the off-centre superstore development became more the norm (Davies and Sparks 1989; Guy, 1994). Indeed, it is estimated that by 1988 some $65 \%$ of all new supermarkets were built on edge-of-town sites (National Consumer Council, 1992). It is widely accepted that one consequence of this retail change has been to make access to such stores more difficult for some sections of the community (see for instance Guy, 1988; Westlake, 1993). In basic terms, limits to accessibility can arise from physical, economic and personal constraints. These factors are clearly inter-related. Older people have been recognised as one potentially disadvantaged group for whom access to food stores can be problematic (Westlake, 1993).

It is important to note that following Bowlby's (1979) study of shopping provision and access in Oxford, we consider access to describe the ease with which shopping opportunities can be reached. Clearly, this differs from actual usage of shops, which may still occur despite notable access constraints. Poor accessibility does not necessarily equate with non-usage, or even reduced usage (Westlake, 1993). Bowlby (1979) considered that access is a function of a person's 'potential' mobility (the ease with which they can travel if they so desire). In contrast 'actual' mobility is used to describe the movement actually undertaken. The distinction between these two levels of access is acknowledged as part of this study. Whilst primarily examining usage in terms of food shops visited, the study also considers access in relation to perceived 
ease of access, ability to do own food shopping and whether respondents shop alone or with friends or relatives.

Planning Policy Guidance Note 6 (PPG6) (Department of Environment, 1996) introduced government planning guidance designed to promote development in town centres, increase support for local centres, and enhance accessibility to new retail developments. It has served to regulate off-centre retail development. Within this revised regulatory context, more attention has been placed on the reinvigoration of 'High Street' food retailing and on the potential of the neighbourhood convenience format. However, the drive to re(develop) large, non-central superstores, whilst slowing due to regulatory control, has by no means halted (Wrigley, 1998b).

The significance of local geographies of food retailing and issues of accessibility has also been demonstrated by studies with an emphasis on diet and nutrition (Donkin et al, 1999; Cummings and Macintyre, 1999). Exploring the issue from a dietary perspective, studies mapping access to food shops, for example, have found many small or local stores lacking in the foods required to provide a basic healthy food basket (Donkin et al., 1999). However, whilst larger edge-of-town or out-of-town superstores typically provide a wider range of foods than many other formats, and therefore potentially more healthy food options, they can prove more difficult to access. The Social Exclusion Unit (SEU) (1998) confirmed a need for access to affordable foods, highlighting deprived or remote areas where consumers may not have access to shops with a range of (fresh) foods. The SEU (1998) also identified that independent shops can be up to $60 \%$ more expensive than multiple retailer food supermarkets. 


\section{$\underline{\text { Retail Provision, Access to Food and Health }}$}

Problems in accessing food shops have been identified by the government as a barrier to good health and nutrition (Department of Health, 1999). Recently, the notion of 'food deserts' has entered the debate more widely (Furey et al., 2001; Cummins and Macintyre, 2002; Wrigley et al., 2003). These have been defined as areas where lowincome households (including older people and lone parent families) face poor accessibility to good quality retailing (SEU, 1998). A large-scale interdisciplinary research project concerned with the issue of food deserts has recently been reported upon (Wrigley et al, 2003). Findings from a case-study site at Seacroft and Whinmoor in Leeds reveal how a "retail provision intervention", the redevelopment of the Seacroft district centre around a large Tesco superstore, had a positive impact on both accessibility to, and consumption of, a more healthy diet (Wrigley et al., 2003)

Clearly, the issues of access to food shops and actual shop usage are of importance on a wider scale than simply in those areas defined as food deserts. Older people have long been considered a disadvantaged group in terms of their ability to access food shops (Bromley and Thomas, 1995; McKie, 1999). The access issues faced by this group are therefore worth investigating further.

A report by the Gerontology Data Service (GDS) with Age Concern, England (1996) highlighted the fact that $27 \%$ of people aged $70-79$ in Great Britain found it impossible to do their own shopping. The same report identified that $50 \%$ of men and $32 \%$ of women in this age group did not have access to a car, and that a third of people over 70 years of age had difficulties using public transport (Age Concern, 
1996). Current UK government policy includes community-level initiatives aimed at improving quality of life and increasing independence in older people through better nutrition and good health. In particular, the government White Paper 'Our healthier nation' outlines a strategy for health in the UK (Department of Health, 1999). This approach hinges on increasing the length of people's lives and the number of years spent free from illness. The government endorses good nutrition as a means to ensuring good health and acknowledges that this is strongly related to education and the availability of 'healthy' foods (Department of Health, 1999).

\section{Dietary Variety and Attitudes and Beliefs}

Food choice research has found that older people who experience the greatest difficulties in food shopping are at the greatest nutritional risk (Herne, 1995). Previous research involving the shopping behaviour of older people has indicated that they may implement coping strategies in order to continue to access food in a way that enables them to manage and maintain their independence (McKie, 1999; Leighton and Seaman, 1997; Hare et al, 1999). These coping strategies include shopping more frequently or with friends or relatives, and using local shops in order to choose foods. This latter strategy reduces older people's reliance on others purchasing foods on their behalf. However, to date there has been relatively little detailed research conducted into the relationship between the food shopping habits of free-living older people and their dietary variety.

Current UK health policy recommends increasing the variety of foods in the diet in order to maintain good health (Department of Health, 1992; 1999). Greater food variety can contribute to greater nutritional adequacy (Hodgson et al, 1994) and the 
advantages to eating a variety of foods are numerous. Whilst numerous studies have examined the relationship between diet and health (see for instance COMA, 1992; Herne, 1995; Finch et al, 1998), most have used a nutrient-based approach, both to describe and quantify diet intake. Less attention has been given to dietary variety, which allows for the study of intake of foods.

Older people have been identified as a group that consumes particularly monotonous and nutritionally inadequate diets (Drewnowski et al, 1997). Social isolation, low income, impaired health and low levels of physical activity have been found to affect eating habits and nutritional status among this group (Drewnowski et al, 1997). Older people are encouraged to consume more varied diets in order to ensure adequate nutritional intakes (Department of Health, 1992).

Finally, reference must be made to the potential significance of attitude to diet in informing any relationship between food store usage, access and dietary variety. The potential of 'nutrition knowledge' and of attitudes and beliefs to influence food selection has been demonstrated in both psychological and food choice research (Ajzen, 1991; Herne, 1995). Further, it has been suggested that whilst individuals may be capable of informed choices they often lack the opportunity to act on them due to physical, economic or cultural constraints (Shepherd, 1989; Davies, 1981; Webb and Copeman, 1996).

More particularly, McIntosh et al (1990) studied the relationship between beliefs about nutrition and dietary practises of older people. The study found that beliefs concerning nutrition affected nutrient density in the diet. Other studies have found 
that perceived taste and beliefs regarding healthy eating were more important factors in the food selection of older people than price, convenience or prestige (Krondl et al, 1982). Recent food choice research has found numerous and varied definitions of healthy eating. Older people tend to perceive 'healthy' eating in terms which may not relate to nutritional guidelines, with many perceiving their diet to be more or less healthy than it actually was (Povey, 1998).

\section{Conceptualising the Problem: Food Store Access and Dietary Variety}

In light of the above literature review, Figure 1 presents a conceptual framework for the exploration of the relationship between store usage, access to food retail provision and dietary variety. Potentially influential variables are annotated with the author(s) of relevant research. From a review of the framework, two particular points are evident.. First, the potentially complex, multi-factored nature of any such relationship. Second, the existence of a considerable amount of academic work that explores particular aspects of this issue, either singularly or in combination, albeit from a variety of different perspectives. The framework acts as a context for the analysis that follows. We also believe that it may be of benefit to other researchers exploring the issue of food shopping among older people.

For the purposes of this paper, emphasis is placed on issues of physical access. As we discuss below, this was the theme identified most commonly in initial focus group research. Consequently, other factors including income and price variation (factors affecting economic access), store choice and attitude are not focussed upon here, 
although the wider data collection allows for an assessment of their influence. The variables considered in this paper are annotated in bold typescript in Figure 1, and the possible relationship between store usage, access and dietary variety is shown as a broken line.

\section{Figure 1 here}

This study explores the food shopping behaviours (store usage and physical access) of a sample older people residing in the town of Guildford, south-east England. Figure 2 provides a map of Guildford Borough showing ward boundaries. Guildford was chosen for several reasons. First, broadly speaking it has patterns of retail provision typical of many similar sized provincial towns; comprising of a concentrated urban centre, with edge-of-town and out-of town superstore development and several district and local centres across the borough (See Figure 3). Second, the study area is partially urban and partially rural in character. Therefore, it has the potential to highlight food access issues of older people from different socioeconomic environments. Finally, it provides a contrast to some of the existing research on food retailing, accessibility and diet. As we have noted, one strand of this has focussed on possible food deserts. Another has looked at the shopping behaviour of older people have focused in urban and rural Scotland. Here aspects of diets, health beliefs and facilities available to older people in terms of social support differ from those in England (McKie, 1999. Hare et al, 1999).

Figure 3 shows the food retail provision in Guildford Borough (Guildford Borough Council, 2002). The map is based on Guildford Borough Council's Environmental Health Office list of food shops. This is reviewed on an annual basis, and classifies 
food retail provision as described in the key to Figure 3. A superstore, for instance, is defined as a shop with more than 3,000 square metres of floor space. There are two such stores indicated in Figure 3. These are the Sainsbury store in Merrow and Burpham ward and the Tesco store in Onslow ward. There is also a smaller town centre based Sainsbury supermarket located in Holy Trinity ward, which proved an important food-shopping destination for many respondents to this study. A food retailer is defined simply as a retailer where food is available to purchase. It is not necessarily the main product sold by the retailer. While acknowledging that the definitions adopted by the Guildford Borough Council report are not those typically used in the retail literature (see for instance Guy, 1994), it nonetheless provides a useful means of assessing levels of food retail provision across the borough.

\section{Figures 2 and 3 here}

\section{Methodology}

A multi-stage methodology was employed to explore the issues of food store usage, physical access and dietary variety among older people. A variety of methods were employed, viz. focus groups, a consumer questionnaire, a food frequency questionnaire (FFQ) and a dietary variety score instrument.

\section{$\underline{\text { Focus Groups }}$}


The purpose of the focus groups was to establish the main food shopping issues considered important by older people residing in Guildford. In total eight focus groups were conducted to examine their views and perceptions. A total of 32 people took part in focus group sessions, ten male and 22 female. Respondents were aged between 65 and 91 years. Participants were recruited among day centre attendees in Guildford. Five main themes were identified from content analysis of the data. These were: access to food shops, access within food shops, social aspects of food shopping, price and choice.

\section{Consumer Questionnaire}

An interviewer-administered questionnaire was developed and piloted. Questions were developed on the basis of an extensive literature review and the previously described focus groups. Questions included whether respondents shopped for themselves, where they shopped most often to conduct their main food shop, how they reached that store, how easy they found it to reach that store and whether they shopped alone or with others. Socio-demographic data were collected for each respondent including age, gender, previous occupation and amount spent per week on food.

Respondents were recruited randomly from day centres within Guildford Borough. 112 older people over 60/65 years completed both the consumer questionnaire and 
the FFQ, the sample consisting of 21 men and 91 women. Of these, 29 were 74 years of age or under. It is acknowledged that as the study participants visited a day centre they may have consumed available meals during a visit. This may of course influence dietary variety to an extent. However, it is not feasible in research of this type to control for all foods eaten. For example, respondents may also eat with family and friends.

Older people were interviewed at day centres in the Send, Ash and Onslow wards (see Figure 2). The Send and Ash wards are classified as rural, while Onlsow is classified an urban ward (Guildford Borough Council, 1999). Respondents who took part in the study resided in 15 of the 21 wards in Guildford Borough. Onslow ward contains a Tesco superstore and borders Guildford town centre. Ash ward has a district shopping centre and Send ward a local shopping centre (Guildford Borough Council, 1999). Both are more distant from Guildford town centre.

\section{$\underline{\text { Dietary Intake }}$}

Usual dietary intake was assessed by the FFQ developed and validated by Geekie (1999). Data were used to determine a food product variety score for each subject, where all foods from the designated food groups listed in the FFQ were recorded (see Hodgson et al, 1994). In addition, to take account of variety within groups, the identification of food types within these groups was undertaken, as an improvement in measuring variety was found when both major and minor food groups were included in the dietary variety score (Krebs-Smith et al, 1997). 
Food groups were based on the format of the FFQ and included groups such as meat, fish, bread products, fruit, vegetables, meat and vegetables dishes, dairy products, cheese and poultry (Geekie, 1999). Food types were then identified within each group. For example, within the food group bread, white bread, granary bread and crisp bread were considered individual foods potentially contributing different nutrients to the diet. Mixed dishes were scored as individual dishes as they are presented in the FFQ. This is a common method when examining variety (Hodgson et al, 1994; Drewnowski et al, 1997; Marshall et al, 2001). The sum of these food group scores gives a total variety score. The total food variety score derived from the FFQ was

81. The variety in the diets of this older population was measured according to food consumed over a one-week period. Food portions were not measured. Dietary variety scores are a qualitative indicator rather than a measure of diet.

Each food eaten over the course of one week was given a score of one. The food only needed be eaten once to be included in the score and any additional consumption of this food type was not recorded, as it would not contribute to increased food variety.

\section{$\underline{\text { Results }}$}

\section{$\underline{\text { Focus Groups }}$}

The main issue reported during focus group research was that of usage of and physical access to food shops. As the following focus group data reveal, this issue was remarked upon in a variety of contexts including, in particular, the changing structure and geography of retail provision in Guildford, the importance of 
maintaining control over food choice and the use of so-called 'coping strategies' in overcoming perceived accessibility constraints.

First, structural and locational changes in food retailing provision in Guildford town were mentioned frequently. These were considered to have exacerbated the problem of access for many participants. Like many other towns, Guildford has seen its food multiples relocate much of their capacity to larger, non-central sites, and independent food shops have declined in number. These changes were a cause of concern for some of those interviewed:

"When they built the Tesco on the other side of town, they closed the one in the town centre" (3B).

“There aren't any others [food shops], not in Guildford, only on the other side [of town]....Then it means another bus... This is just the closest one...the others are too difficult to get to" (3, A/B).

"Well, they've taken them all out of the middle and put them round the edge... What use is that to those of us who don't have cars?" (3F).

Many of those undertaking food shopping in Guildford town centre also reported mobility difficulties as a result of its 'hilly' topography.

Those who could access supermarkets and superstores, whether the edge-of-town or out-of-town superstores, or the smaller Sainsbury supermarket in the town centre, 
often considered themselves to be fortunate. This was reflected in the following typical responses:

"I'm lucky, I can get to the supermarket easily" (3 J).

"My friend goes to get her shopping at the same time and she's doing me a favour really" $(3 \mathrm{H})$.

Some respondents overcame access constraints by arranging to shop with a friend or relative, which frequently was considered not only to contribute to the enjoyment of the 'shopping experience' but also to allow respondents to purchase heavier goods such as bags of potatoes. Shopping with others was seen by some as a way of maintaining independence. However, some other respondents reported feeling a loss of independence, by being unable to shop for themselves and having to rely on other people for help. Independence has been identified as a highly valued aspect of older age (McKie, 1999). This is reinforced by the focus group findings. Responses included:

"I only get to the shop once a fortnight, but my friend takes me so it's much easier, and I can get enough to tide me over" $(3 \mathrm{H})$

As one would expect, several respondents stated that price and value for money were important considerations when shopping for food. However, the other main issue reported, in addition to usage and physical access, was that of maintaining the ability to choose foods for oneself and developing methods of reaching food shops; the 
previously discussed coping strategies. The importance of these factors is shown in the following responses from focus group participants:

"My one pleasure is being able to choose what I eat for myself" (2K).

"I have to think about the best way all round to get what I need" ( $2 \mathrm{G})$.

This theme was also revealed by the changes that some older people reported making to their shopping behaviours in order to maintain a level of independence and choice. This could involve shopping at a less preferred store in order to maintain the ability to visit stores and choose foods for themselves.

For those who did not do their own food shopping, many had friends or relatives who purchased their food. These friends or relatives were reported to know what food was liked, although more often than not in these cases the respondents reported providing a list, meaning they maintained a level of choice and control over the foods bought for them. Those who had shopping bought by carers seemed less able to obtain the foods they desired. A common response among this group was:

"The girl that does my shopping she's very good ... sometimes she'll bring things I don't want... Still, you've got to be grateful for what you get" (2 C).

This last comment emphasised the overall feeling of this group of older people that if they could not obtain foods independently they felt burdensome on those who bought 
it for them. In addition some members of this group reported missing out on social interaction with others, as they were unable to get out of the house on a regular basis:

"I used to like walking around seeing what was going on and what was new, whether there was anything else I fancied you know. I just can't do it any more, it's very difficult" (2 B).

Social interaction and 'getting out' appeared closely linked to aspects of store choice. Several respondents stated that they missed the social environment provided by local, independent stores that had since closed in their area (see also Baron et al. 2001). Supermarkets providing cafés were enjoyed by many of those shopping with friends or relatives and were reported as providing a focal point for interaction among those using dial-a-ride services. Many of those shopping with friends and relatives saw the benefit of spending time with others and being able to choose foods themselves. However, the issue of choice became apparent here in the sense that the store visited was not always the store of choice, many respondents stating that they shopped at a given store simply because a friend or relative did.

The results of these focus groups suggest that some older people in this group feel a need to compromise when food shopping. They do so in order to buy their own food and maintain important levels of independence and control over their food shopping experience. This need to compromise is perhaps not to be unexpected. Indeed, it is suggested that older consumers do not differ so greatly from other age groups in terms of compromising to reach food shops (Hare et al, 1999). Other age groups 
have been reported as compromising in terms of time, choice of shop and price (National Consumer Council, 1992).

Having established that some of the older people questioned as part of this research have to compromise in order to shop for foods effectively, the extent to which this affects dietary variety is now examined.

\section{Food Shopping and Dietary Variety}

Table 1 provides a description of the sample characteristics for respondents who completed the consumer questionnaire and the FFQ.

\section{Table 1 here}

In total, 112 respondents completed the consumer questionnaire. Of the 74 respondents who did their own food shopping, 47 shopped once a week; 59 shopped at a supermarket, either the two large non-central superstores noted in Figure 3 or the smaller Sainsbury supermarket in Holy Trinity ward. Proximity was the main reason stated for shopping at a particular store. A total of 37 respondents used buses or walked to food shops, the remaining 37 respondents either drove or were driven by a friend or relative.

Of those who did not do their own food shopping, 25 of the 38 respondents relied on a friend or relative and 3 used the Iceland home delivery service. The remainder had their shopping bought by carers; 16 respondents did not know where their food was 
purchased and 35 of 38 stated they did not request their shopper to visit a certain store. Despite this, 33 respondents stated they had moderate to complete control over the foods that were purchased for them.

All 112 respondents completed the interviewer administered FFQ. Using the dietary variety score, the number of different foods consumed in a week was calculated for each respondent. The total number of food types included in the score was 81 . The mean dietary variety score for this population was 27.5 (out of a maximum of 81 ), indicating that on average 27.5 different food types were consumed by respondents in a given week (women $-\chi=27.9$, range $=18-41$, men $-\chi=25.8$, range $=17-34$ ). It should be noted that it can be difficult to ascertain where variety comes from in the diet based on total variety score.

It has been suggested that a food variety score of at least 15 foods over one week should be considered as a minimum for nutritional adequacy, provided that the majority of this variety comes from plant sources (Hodgson et al, 1994). Vegetable consumption was the largest contributor to dietary variety of this sample of older people and the minimum variety score was 17 . These data suggests adequate dietary variety.

Foods were consumed from the majority of the food groups. However, within the food groups relatively few food types were eaten. For example, of the 112 respondents eating foods from the potatoes, pasta and rice food group, 77 ate only potatoes in the week during which diet was recorded. The biggest contribution to 
dietary variety was fruit and vegetables, with an average of 6.45 different vegetables and 2.93 different fruit types consumed per week.

\section{$\underline{\text { Analysis }}$}

For the purposes of analysis the population was divided into two groups, those who ate above and those who ate below the mean number of food types found. Chi square tests were conducted to examine whether dietary variety was influenced by store usage, physical access related variables and socio-demographic variables. The results are shown in Table 2.

\section{Table 2 here}

Dietary variety was cross tabulated against the following variables: Do/Don't do own food shopping; method of transport used for shopping visit; perceived ease of shopping experience; main food shop visited - whether supermarket/superstore or 'other'; distance travelled to the store most often visited; shop alone/ shop with others. The analysis aimed to examine whether a simple relationship existed between store usage and access factors and dietary variety. The research (alternative) hypotheses considered that someone who did not do their own food shopping, who used public transport or walked to the store, who visited an 'other' store type (i.e. not a supermarket/superstore) for their main food shop would have a lower dietary variety score than other respondents. The socio-demographic variables of marital status, live alone/with others, and gender, together with amount spent per week on 
food shopping, were also examined. Table 2 gives the chi square results from these cross tabulations.

The results reveal that chi square analysis found no significant relationship between the dietary variety scores of the respondents and either basic measures of store usage and access or socio-demographic status. A logistic regression analysis was also conducted to examine the relationship between selected variables and dietary variety. However, with the exception of gender, none of the variables presented in Table 2 was found to have a significant effect on dietary variety. Gender was found to be significantly related to dietary variety score regardless of food shopping habits $(\mathrm{p}=$ 0.048). However, the model was not found to be well fitting.

\section{$\underline{\text { Discussion }}$}

Analysis of the questionnaire data collected for this study reveals no simple relationship between store usage and dietary variety, or between physical access to food shops and dietary variety. The former may be expected, as access would appear to influence usage. Many of those who shopped at supermarkets primarily did so because they relied on friends or relatives to reach food stores, and they visited the store the friend or relative did. Therefore as a result of finding alternative methods of reaching food shops, usage appears unaffected. Indeed coping strategies such as those suggested may in fact have improved usage compared to previous shopping experiences, in terms of respondent's ability to reach a supermarket. However, this may be at the expense of convenience, store choice or indeed food choice. 
The absence of a relationship between physical access to store and dietary variety needs further explanation. Such explanation may come in part from a review of the findings of the focus group analysis. This suggests a complex relationship of interwoven factors at play. Certainly, the focus group research reveals some older people do have to think in detail about the best way to get what food they need and want (see also McKie, 1999; Gunter, 1998). Even if taken to a store, they may not necessarily be taken to their preferred shop. Despite this, no relationship is found to exist between variables such as 'perceived ease of access' and dietary variety. This might indicate that older consumers in the sample accept the need to compromise in their food shopping activities, for instance adopting coping strategies in order to maintain an active independent lifestyle, and do not necessarily relate the adoption of such strategies to poor ease of access. More research needs to be undertaken to determine whether this is so.

Within the constraints of the present research it is difficult to judge whether access affects the overall quality of foodstuffs available. More than three quarters of respondents who undertook their own food shopping used supermarkets to conduct their main food shop, suggesting that, in relation to physical access at least, for this group food choices were not limited in terms of the variety and quality of foodstuffs available. However, in the absence of more detailed food intake data, the dietary variety score cannot be extrapolated to provide a detailed assessment of the overall quality of the diet of particular sub groups within the overall sample. 
More widely, the focus group findings also highlight older people's emphasis on maintaining independence and social contact. Cooper et al (1999) note that social support was important for maintaining health and dietary variety. The social environment and purchasing of food in the company of others was considered to have affected dietary variety in the present study, increasing the number of foods eaten. However, attitude to diet, meals taken with relatives or others and food preparation also need to be taken into account.

In terms of the types of foods consumed by this population of older people, the pattern of consumption among the sample was similar to that found in other studies (Cooper et al, 1999) in that white bread, potatoes and sugar in tea were most frequently consumed. Webb and Copeman (1996) suggest that the consumption of these foods may be related to older people's perceptions. These may make them less likely to consume a variety of foods from one source due to a preference for more traditional foods and because of later exposure in life to certain food groups.

There was no significant difference in the dietary variety of older people in Guildford Borough according to any of the demographic measures examined. Women were found to have more varied diets than men (women, $\chi=27.9$, range $=18-41$, men $\chi=$ 25.8, range $=17-34)$. However, given the gender distribution of the sample and the limitations of using dietary variety scores, it is not possible to discern whether the female respondents have a healthier diet as a result of a greater mean variety score.

Clearly, store usage and access among older people is a complex issue. This paper has highlighted various related aspects of the problem, linking them to the important 
issues of dietary variety and health. The research demonstrates the importance of understanding the social and organisational factors potentially leading to poor quality diets and the need to examine the role of formal and informal networks in enhancing health-promoting food provisioning among older consumers. These remain important areas for discussion, research and policy debate. Studies that directly explore older consumers' perceptions and behaviours in food shopping in a diversity of geographical and socio-economic environments, and that acknowledge the importance of a multi-disciplinary perspective have an important role to play in this contribution. This study represents a contribution to such an emerging literature.

\section{$\underline{\text { References }}$}

Age Concern (1996) 'Getting Around After 60', Age Concern, London.

Ajzen, I. (1991) 'The Theory of Planned Behaviour', Organisational Behaviour and Human Decision Process, 50, pp 179-211.

Axelson, M.L. and Penfield, M.P. (1983) 'Food and nutrition related attitudes of elderly persons living alone', Journal of Nutrition Education, 15(1) pp 23-27.

Baron, S., Harris, K., Leaver, D. and Oldfield, B. (2001) 'Beyond convenience: the future for independent food and grocery retailers in the UK', International Review of Retail, Distribution and Consumer Research, 11(4), pp 395-414.

Bowlby, S.R. (1979) 'Accessibility, mobility and shopping provision' in Goodall, B. and Kirby, A., (eds) Resources and Planning, Pergamon Press, Oxford.

Bromley, R.D.F. and Thomas, C.J. (1995) 'Small town shopping decline and inconvenience for the disadvantaged', International Review of Retail, Distribution and Consumer Research, 5(4), pp433456.

Cooper, H., Ginn, J. and Arber, S. (1999) Health related behaviour and attitudes of older people; a secondary analysis of national datasets, Health Education Authority, London.

Cummins, S. and Macintyre, S. (1999) 'The location of food stores in urban areas: a case study in Glasgow', British Food Journal, Vol. 101 (7), pp 545-553.

Davies, K. and Sparks, L. (1989) 'The development of superstore retailing in Great Britain 1960-1986: results from a new database', Transactions of the Institute of British Geographers, 14(1), pp 74-89.

Davies, L. (1981) Three score years...and then? A Study of the Wellbeing of the Elderly, William Heinemann Medical Books, London.

Department of Environment (1996) Planning Policy Guidance Note 6: Town Centres and Retail Development, HMSO, London. 
Department of Health (1992) Nutrition in Elderly People. A Report by the COMA Working Party, HMSO, London.

Department of Health (1999) Saving Lives: Our Healthier Nation, HMSO, London.

Donkin, A.J.M., Dowler, E.A., Stevenson, S.L. and Turner, S.A. (1999) 'Mapping access to food at a local level', British Food Journal, 101(7), pp 554-564.

Drewnowski, A., Ahlstrom-Henderson, S., Driscoll, A. and Rolls, B.J. (1997) 'The Dietary Variety Score: assessing diet quality in healthy young and older adults', Journal of the American Dietetic Association, Vol. 97( 3), pp 266-271.

Finch, S., Smithers, G., Doyle, W., Lowe, C., Bates, C. J., Prentice, A. and Clarke, P.C. (1998) National Diet and Nutrition Survey of People Aged 65 and Over, TSO, London.

Furey, S., Strugnell, C. and McIlveen, H. (2001), 'An investigation of the potential existence of 'food deserts' in rural and urban areas of Northern Ireland', Agriculture and Human Values, Vol. 18, pp447457.

Geekie, M.A. (1999) 'Promoting a reduction in the consumption of dietary fat: the role of perceived control, self-efficacy and personal dietary information', Unpublished $\mathrm{PhD}$ thesis, University of Reading, UK.

Gregory, J., Foster, K., Tyler, H. and Wiseman, M. (1990) The Dietary and Nutritional Survey of British Adults, HMSO, London.

Guildford Borough Council (1999) Guildford Borough Local Plan (Deposit version). Guildford Borough Council, Guildford.

Guildford Borough Council (2001) Environmental Health Office List of Food shops in Guildford Borough, Guildford Borough Council, Guildford.

Guildford Borough Council (2002) Guildford Borough Plan, Guildford Borough Council, Guildford.

Gunter, B. (1998) Understanding the Older Consumer: the Grey Market, Routledge, London.

Guy, C.M. (1988) 'Retail planning policy and large grocery store development: A case study in South Wales', Land Development Studies, 5, pp 31-45.

Guy, C.M. (1994) The Retail Development Process: Location, Property and Planning, Routledge, London.

Hare, C., Kirk, D. and Lang, T. (1999) 'Identifying the expectations of older food consumers: More than a 'shopping list' of wants', Journal of Marketing Practice: Applied Marketing Science, 5 (6-8), pp 212-232.

Herne, S. (1995) 'Research on food choice and nutritional status in elderly people: a review', British Food Journal, 97(9), pp 12-29.

Hodgson, J.M., Hsu-Hage, B. HH., Wahlquist, M.L. (1994) 'Food variety as a quantitative descriptor of food intake', Ecology of Food and Nutrition, Vol. 32, pp 137-148.

Krebs-Smith, S.M., Smickilas-Wright, H., Guthrie, H.A. and Krebs-Smith, J. (1987), 'The effects of dietary variety in food choices on dietary quality', Journal of the American Dietetic Association, Vol. 80, pp523-529.

Krondl, M., Lau, D., Yurkiw, M. and Coleman, P.H. (1982) 'Food use and perceived food meanings of the elderly.' Journal of the American Dietetic Association. 80, pp 523-529. 
Lang, T. and Caraher, M. (1998) 'Access to healthy foods, part 2: Food poverty and shopping deserts. What are the implications for health promotion policy and practice' Health Education Journal, 57, pp 202-211.

Leighton, C. and Seaman, C. (1997) 'Food retailing: An opportunity for meeting elderly consumers needs', Nutrition and Food Science, pp i-xi.

McIntosh, W.A., Kubena, K.S., Walker, J., Smith D. and Landmann, W.A. (1990) 'The relationship between beliefs about nutrition and dietary practises of the elderly", Journal of the American Dietetic Association, Vol. 90 No. 5, pp671-676.

McKie, L. (1999) 'Older people and food: independence, locality and diet', British Food Journal, 101(7), pp 528-536.

McKie, L., MacInnes, J., Donald, S. and Peace, H. (2000) ' The food consumption patterns and perceptions of dietary advice of older people', Journal of Human Nutrition and Dietetics, 13, pp 173183.

Marshall, T.A., Stumbo, P.J., Warren, J.J. and Xie, X. (2001) 'Inadequate nutrient intakes are common and are associated with low dietary variety in rural, community dwelling elderly', Journal of Nutrition, Vol. 131, pp 2192-2196.

National Consumer Council (1992) Your food, whose choice?, HMSO, London.

Office of National Statistics (2000) Population Trends100 (Summer), TSO, London.

Office of National Statistics (2002) Population Trends110 (Winter), TSO, London

Povey, R., Conner, M., Sparks, P., James, R., and Shepherd, R. (1998) 'Interpretations of healthy and unhealthy eating and implications for dietary change', Health Education Research, 13(2), pp 171-183.

Shepherd, R. (1989) (ed) Handbook of the Psychophysiology of Human Eating, Wiley Publications, London.

Smith, G.C. (1991) 'Grocery shopping patterns of the ambulatory urban elderly' Environment and Behaviour 23(1) pp86-114.

Social Exclusion Unit (1998) Bringing Britain Together: A National Strategy for Neighbourhood Renewal, HMSO, London.

Webb, G.P. and Copeman, J. (1996) The Nutrition of Older Adults. Arnold Publications/ Age Concern England, London.

Westlake, T. (1993) 'The disadvantaged consumer: problems and policies', in Bromley, R. and Thomas, C. (eds) Retail change: Contemporary issues. UCL Press, London.

Wrigley, N. (1998a) 'How British retailers have shaped food choice' in Murcott, A. (ed) The Nations Diet: The Social Science of Food Choice, Longman, London.

Wrigley, N. (1998b) 'PPG6 and the contemporary UK food store development dynamic' British Food Journal, 100(3), pp 154-161.

Wrigley, N., Warm, D. and Margetts, B. (2003) 'Deprivation, diet and food retail access: findings from the Leeds 'Food Deserts' Study', Environment and Planning A, Vol. 35 , No. 1, pp151-188. 
Table 1: Sample characteristics

\begin{tabular}{|c|c|c|}
\hline Variable & $\begin{array}{l}\text { Number of } \\
\text { respondents }\end{array}$ & $\begin{array}{l}\text { Total number of } \\
\text { respondents }\end{array}$ \\
\hline $\begin{array}{l}\text { Food Shopping } \\
\text { Do own food shopping } \\
\text { Do not do own food shopping } \\
\end{array}$ & $\begin{array}{l}74 \\
38\end{array}$ & 112 \\
\hline $\begin{array}{l}\text { Method of transport } \\
\text { Public transport (e.g. bus) } \\
\text { Private transport (e.g. drive/driven) }\end{array}$ & $\begin{array}{c}37 \\
37 \\
\end{array}$ & 74 \\
\hline $\begin{array}{l}\text { Perceived ease } \\
\text { Easy to get to shop } \\
\text { Difficult to get to shop }\end{array}$ & $\begin{array}{l}60 \\
14 \\
\end{array}$ & 74 \\
\hline $\begin{array}{l}\text { Shop most often visit for main food shop } \\
\text { Shop at supermarket/superstore } \\
\text { Shop at "other" store }\end{array}$ & $\begin{array}{l}59 \\
15\end{array}$ & 74 \\
\hline $\begin{array}{l}\text { Distance to food shop most often visited } \\
\text { Up to } 2 \mathrm{~km} \\
>2 \mathrm{~km}\end{array}$ & $\begin{array}{l}52 \\
22\end{array}$ & 74 \\
\hline $\begin{array}{l}\text { Marital Status } \\
\text { Single } \\
\text { Married } \\
\text { Widowed/Divorced }\end{array}$ & $\begin{array}{c}5 \\
10 \\
59\end{array}$ & 74 \\
\hline $\begin{array}{l}\text { Housing } \\
\text { Live alone } \\
\text { Live with partner or family }\end{array}$ & $\begin{array}{l}63 \\
11\end{array}$ & 74 \\
\hline $\begin{array}{l}\text { Shopping behaviour } \\
\text { Shop alone } \\
\text { Shop with others }\end{array}$ & $\begin{array}{l}39 \\
35\end{array}$ & 74 \\
\hline $\begin{array}{l}\text { Gender } \\
\text { Male } \\
\text { Female }\end{array}$ & $\begin{array}{l}21 \\
91\end{array}$ & 112 \\
\hline $\begin{array}{l}\text { Amount spent on food/week (f) } \\
<25 \\
26-50 \\
>50\end{array}$ & $\begin{array}{l}85 \\
17 \\
10\end{array}$ & 112 \\
\hline
\end{tabular}

$N . B$ where $n$ total $=74$ the variable was only measured for those who did their own food shopping 
Table 2: Chi Square analysis to examine the relationship between mean dietary variety score, shop usage and access, and socio-demographic variables.

\begin{tabular}{|c|c|c|}
\hline Variable vs Dietary Variety Score & $\begin{array}{l}\text { Chi Square } \\
\text { Value }\end{array}$ & $P$ value \\
\hline Food shopping (do own/do not do own) & 0.335 & 0.846 \\
\hline Method of transport & 1.640 & 0.650 \\
\hline Perceived ease & 1.442 & 0.486 \\
\hline Shop most often visit for main food shop & 0.472 & 0.492 \\
\hline Distance to food shop most often visited & 0.128 & 0.721 \\
\hline Marital Status & 3.76 & 0.28 \\
\hline Housing (live alone/live with others) & 2.69 & 0.26 \\
\hline $\begin{array}{l}\text { Shopping behaviour (shop alone/shop with } \\
\text { others) }\end{array}$ & 1.01 & 0.79 \\
\hline Gender & 5.69 & 0.17 \\
\hline Amount spent on food per week (£) & 0.15 & 0.993 \\
\hline
\end{tabular}




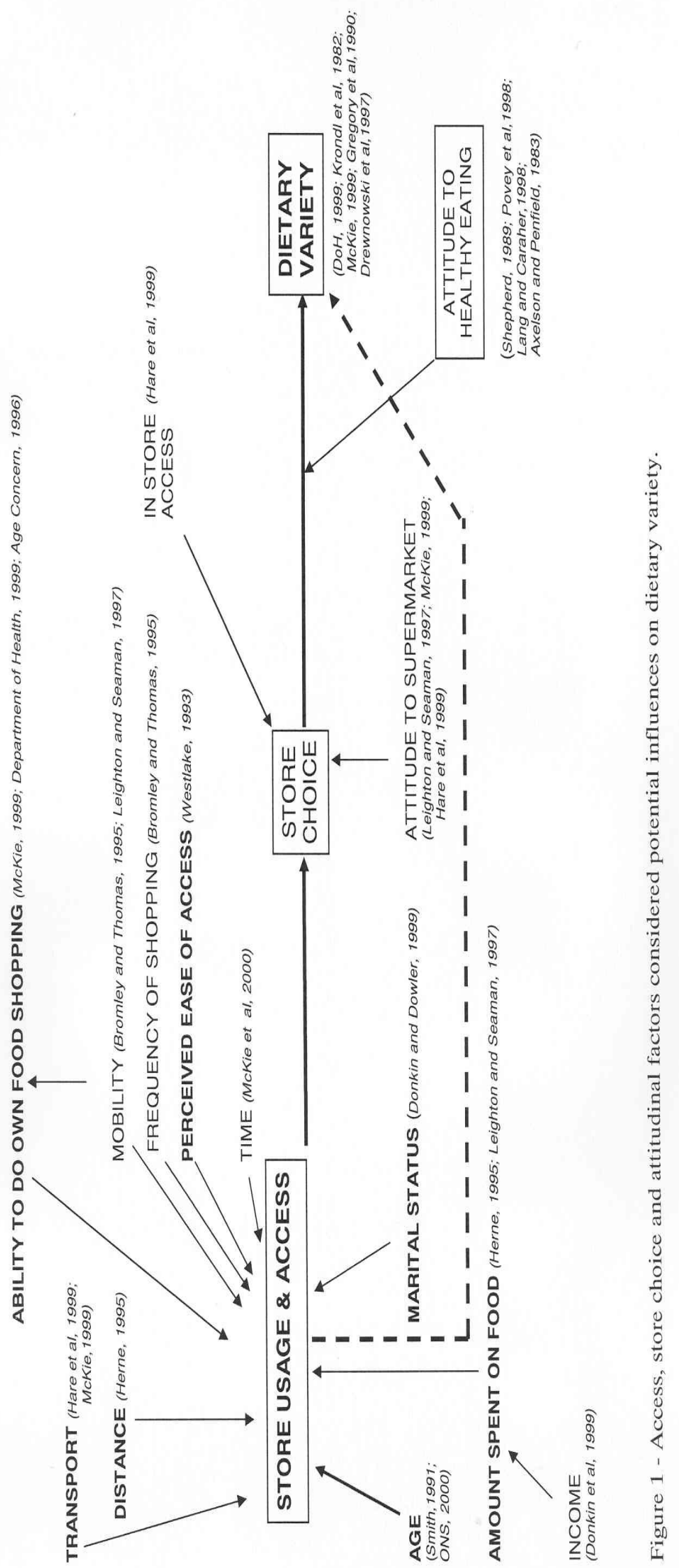

Figure 1 - Access,. 
Figure 2: A Map of Guildford Borough showing ward boundaries

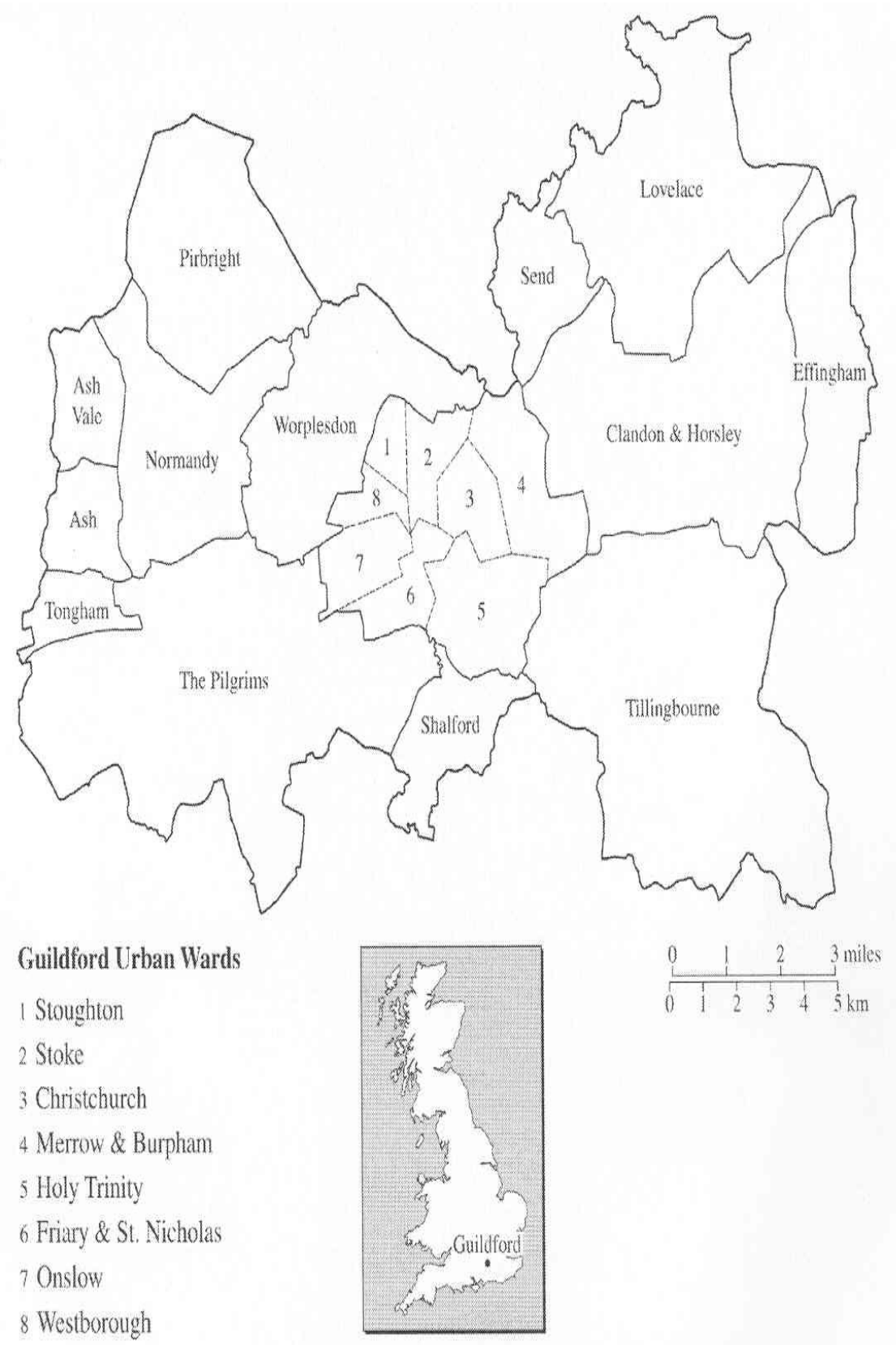




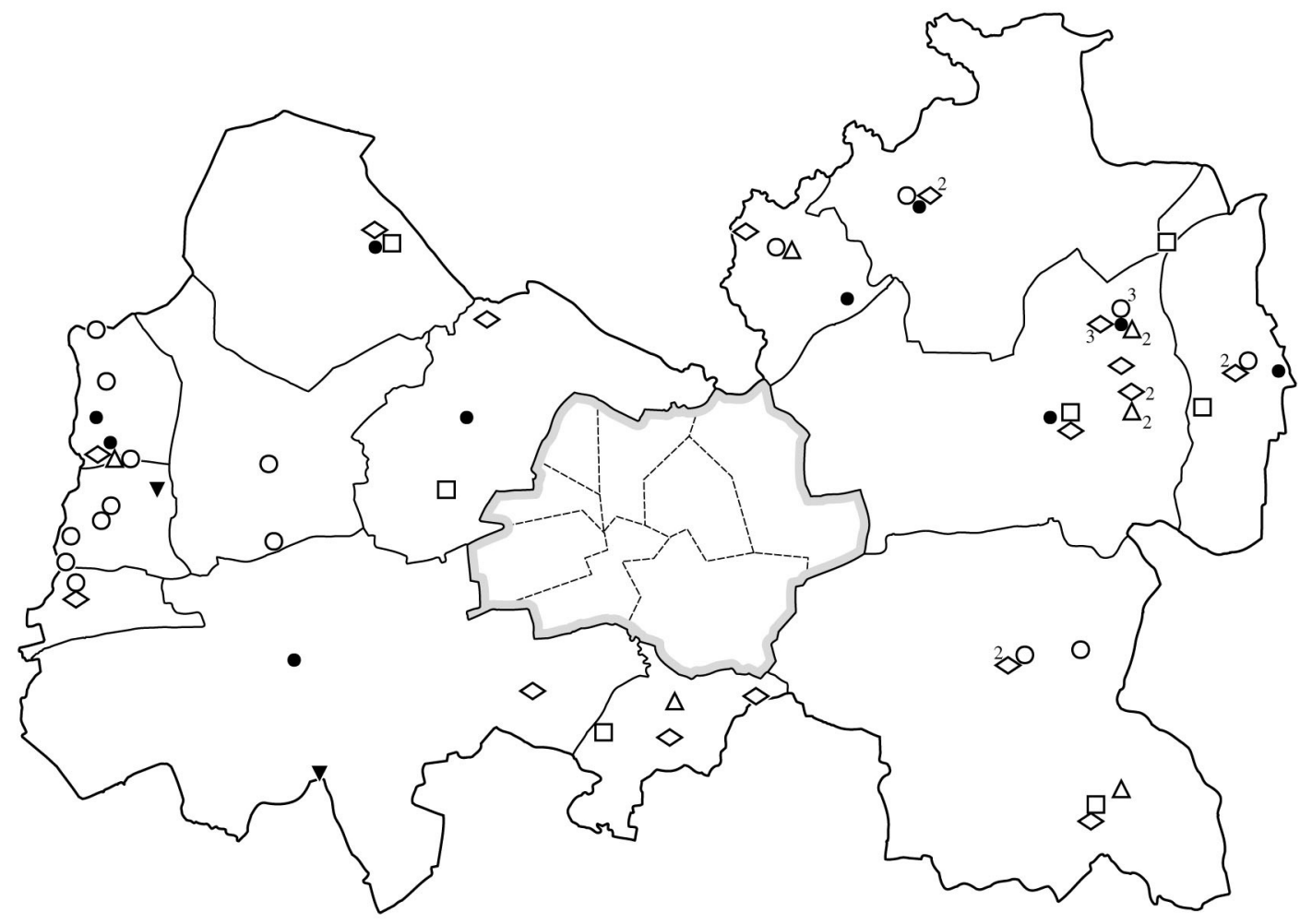

Guildford Urban Wards

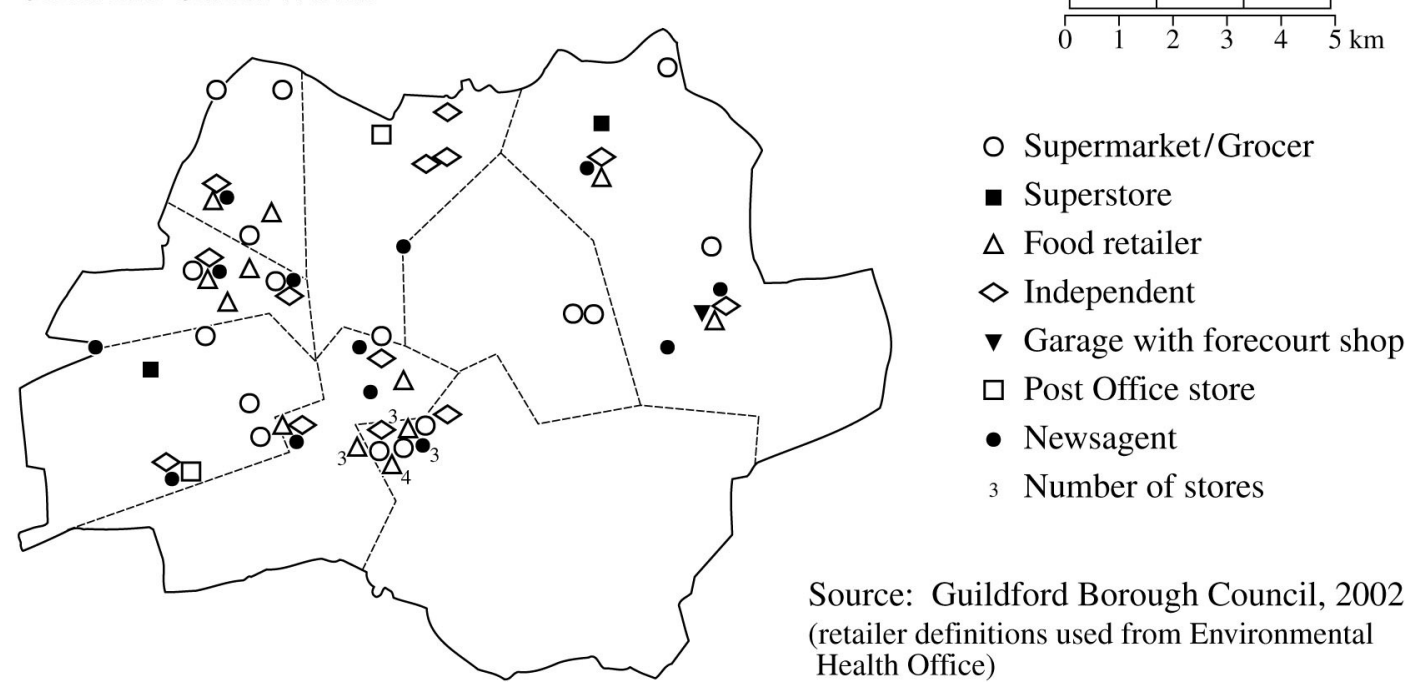

